\title{
Significações Imaginárias Sociais e Novos Modos de Sofrimento no Trabalho: Contribuições a Partir da Sociologia Clínica
}

Social Imaginary's Significations and the New Expressions of Suffering in the Work Environment: Clinical Sociology Contributions

\section{Significações Imaginárias Sociais e Novos Modos de Sofrimento}

\author{
Matheus Viana Braz'1, Francisco Hashimoto2
}

\begin{abstract}
Resumo
O objetivo deste estudo consiste em repensar as antinomias das significações imaginárias sociais do contemporâneo, mormente no que diz respeito aos novos modos de sofrimento e investimentos subjetivos no trabalho. Partimos, pois, do pressuposto que nossa sociedade passa por um processo de transição, de sorte que há a proliferação de significações imaginárias heterônomas, que por sua vez estimulam valores, afetos e ideais específicos. Para além das contribuições do filósofo Cornelius Castoriadis, a partir da Sociologia Clínica e priorizando o cenário laboral, analisamos neste trabalho signos importantes que assumem protagonismo na hipermodernidade, como o crescimento da descrença, pessimismo, individualismo e do investimento na esfera privada, em detrimento da pública. Remetemo-nos, em última instância, a um novo polo de legitimação social, que exprime um código simbólico particular e se ampara na promessa da realização de projetos específicos: ascensão vertiginosa, reconhecimento, visibilidade e destaque social.
\end{abstract}

Palavras-chave: Trabalho. Sofrimento. Sociologia Clínica.Significaçõesimagináriassociais.

\begin{abstract}
The goal of this study is to rethink the antinomies of the social imaginary's significations of the contemporary, regarding the new expressions of suffering and subjective investments in the work environment. In this context, we assume that our society undergoes a transition process in which there is a proliferation of heteronomous imaginary's significations that is stimulating specific values, affections and ideals. Additionally, beyond philosopher Cornelius Castoriadis' contributions, from Clinical Sociology and prioritizing the labor scenario, we studied relevant signs that play a leading role in hypermodernity such as growing disbelief, pessimism, individualism and investment in the private sphere, to the detriment of the public one. Finally, we discussed a new pole of social legitimization, which expresses a particular symbolic code and is supported by the promise of specific projects: vertiginous ascent, recognition, visibility and social prominence.
\end{abstract}

Keywords: Work. Suffering. Clinical Sociology. Social imaginary’s significations.

\footnotetext{
${ }^{1}$ Universidade Estadual Paulista (Unesp-FCLA), Assis, Brasil. E-mail: mvianabraz@gmail.com

${ }^{2}$ Universidade Estadual Paulista (Unesp-FCLA), Assis, Brasil. E-mail: franciscohashimoto@gmail.com
} 
As grandes referências, bem como os heróis e instituições tradicionais históricas da modernidade, não são atualmente mais mobilizadoras de identificação (Aubert, 2004a).A perda de um sentido unificador e de uma identidade estanque é correlata a uma espécie de descentração (ou deslocamento) do sujeito hipermoderno (Hall, 2006). A incredulidade em relação aos metarrelatos (Lyotard, 1986) evidencia uma transformação cultural que culminou em um sujeito sem identidade fixa, cambiante e indeterminado, conforme é representado e interpelado. Trata-se, pois, do indivíduo autorreferente (Ehrenberg, 1991), da efemeridade e da frivolidade (Lipovetsky, 2007), do excesso descontínuo e da diferença (Aubert, 2003; 2004a; 2004b), da apreensão da realidade de um modo cada vez mais plural e versátil.

Para explorar esta questão, contudo, é preciso que nos debrucemos sobre um fenômeno mais amplo, isto é, sobre o que dá esse sentido ao coletivo e, em última instância, às sociedades. De acordo com Gaulejac (2003), nós estamos constantemente buscando sentido para nossas condutas e sociedade (no plano ontológico, sentido para a vida e para a morte). Nessa esteira, vislumbramos em nosso cotidiano agenciar representações conforme uma rede de códigos e significações, para atribuir sentido às nossas vidas e nutrir nossas identidades na ordem social. Ora, cada sociedade se constrói de acordo com a criação de significações que lhe são específicas. A função dessas significações imaginárias sociais (Castoriadis, 2002) se ancora em um tripé dimensional. Elas servem, antes de tudo, para estruturar nossas representações de mundo, cuja especificidade nos localiza na história (nossa sociedade não é a mesma da sociedade romana na Antiguidade Clássica, por exemplo). Em segundo lugar, essas significações designam as finalidades de nossas ações, isto é, nos dão as diretrizes sobre o que deve ou não ser feito, bem como sobre como e por que o devemos fazer. Ora, se admitirmos que nenhuma lei biológica ou natural diz que é preciso adorar Deus, quem cumpre tal função são as representações das escoras religiosas. Por fim, em terceiro lugar, essas significações refletem modos específicos de afetos e sofrimentos. É dizer, a sociedade capitalista do século XIX, segundo Marx, trazia consigo uma série de afetos instituídos socialmente, tais como a inquietude perpétua, as aspirações de mudanças constantes, a sede do novo pelo novo, bem como do mais pelo mais (Castoriadis, 2002).

A operacionalização dessas três dimensões (representações, finalidades e afetos), portanto, se inscreve em instituições particulares, intersectadas na ordem social e cujos modos de subjetivação se distinguem historicamente. Dentre o conjunto de significações imaginárias existentes, de acordo com Castoriadis (2002), a mais 
importante está vinculada à que concerne à própria sociedade como um todo. A forma com que significamos nossa sociedade revela, indissociavelmente, tanto nosso próprio olhar (tal como um exercício de autorrepresentação) e posicionamento sobre ela quanto às formas de investimento na coletividade concreta. Esta, porquanto, somente pode ser idealmente imperecível, quando da presença de sentido e significações (instituídos por ela mesma) considerados também imperecíveis pelos próprios membros da sociedade. Destarte, seja no nível da representação social, seja no nível discursivo, quais correspondentes entrópicos - para além de questões demográficas -, de uma identificação final entre cada um de nós, permitem que nos identifiquemos como a nação brasileira? Onde se encontra o sentido apreendido como imperecível de nossa sociedade? Que sentido atribuímos, no plano social, à autorrepresentação de nossa coletividade? Como compreender as novas formas de sofrimento no trabalho a partir desse prisma? Como apreender a nova economia afetiva e de investimento psíquico no universo laboral?

Sob a óptica da Sociologia Clínica (Gaulejac, Hanique\& Roche, 2012), nos interessamos neste estudo pela compreensão dos avatares e ressonâncias das antinomias imaginárias sociais do contemporâneo, mormente no que diz respeito aos modos de sofrimento e investimentos subjetivos no trabalho. Partimos, pois, do pressuposto de que a sociedade passa por um processo de transição, de sorte que há a proliferação de significações imaginárias heterônomas, que por sua vez estimulam valores, afetos e ideais específicos. Para além das contribuições de Castoriadis (1982; 2002) e priorizando o cenário laboral, objetivamos analisar signos importantes que assumem protagonismo na hipermodernidade, a saber, o crescimento da descrença, do pessimismo, do individualismo, bem como do investimento na esfera privada, em detrimento da pública. Remetemo-nos, em última instância, a um novo polo de legitimação social, que exprime um código simbólico particular e se ampara na promessa da realização de projetos específicos: ascensão vertiginosa, reconhecimento, visibilidade e destaque social.

\section{As Significações Imaginárias Sociais do Contemporâneo}

Tangenciando a discussão supracitada, Palmade (1990) coloca em evidência a crise identitária contemporânea, destacando um processo de enfraquecimento (ou uma falta de apoio) das identificações primárias em nossa sociedade. No plano psicanalítico, a atenção volta-se, sobremaneira, para a tese do apagamento do Complexo de Édipo, isto é, do apagamento das identificações mais estruturantes da identidade, que culminariam em uma 
regressão ao estado do narcisismo. Haveria, portanto, uma separação entre a identidade constituída pelos processos identitários ou defensivos pré-edipianos -e cuja característica é a identidade narcísica -, e as identificações sociais estruturadas pelos valores e normas hegemônicas de nossa sociedade. Castoriadis (2002), nesse sentido, ao evocar a "ascensão da insignificância", dá atenção especial justamente a essa espécie de separação, entre "identidade psicoafetiva" e "identidade social" do sujeito, que carrega em seu bojo a fragilidade das identificações.

No plano sociológico, as transformações de nossa sociedade produziriam, por sua vez, uma clivagem entre a esfera do econômico e político e a esfera do "mundo vivido", que nos remete a traços específicos de nossa cultura e personalidade (Gaulejac, 2010). Em última instância, faz-se referência ao deslocamento de escoras fundamentais dos processos de identificação correlatos a um conjunto de instituições sociais outrora instituídas, tais como a família, a religião, o estado, a habitação e os locais de trabalho (Aubert, 2004; Gaulejac, 2010). Nesse ínterim, para além das teorizações de Palmade (1990), a tese central de Castoriadis (2002) consiste em defender que se consolidou, no fimdo século XX, uma crise das significações imaginárias estruturantes de nossa sociedade que, ao mesmo tempo, produziu uma crise do processo de identificação, agravada e reproduzida pela primeira.

O deslocamento dessas escoras, porém, não se revela, stricto sensu, como condição suficiente e necessária para a instauração de uma crise, uma vez que é possível observá-la em ambientes em que não há, aparentemente, enfraquecimento das escoras de habitação, família etc. É preciso, portanto, analisar a complexidade de nossa reflexão. Embora em alguma medida $\mathrm{O}$ sentido da habitação, para muitas pessoas, esteja bastante vinculado à estabilidade, a noção de localidade se desvinculou da significação que possuía outrora, aproximando-se da errância e sujeitando-se cada vez mais às demandas do mundo do trabalho. O mesmo ocorre com as significações hegemônicas que há, atualmente, acerca da religião, da família e do trabalho em nossa sociedade. Há um deslocamento, de sorte que os modelos familiares tornam-se mais heterogêneos e versáteis, as instituições religiosas assumem cada vez mais avatares artificiais e caricaturais (mascarando interesses privados e distanciando-se de qualquer vinculação com a religiosidade e interioridade), ocupando funções laterais, e o trabalho é substancialmente ressignificado, sofrendo as incidências diretas das novas relações do sujeito com o tempo, espaço, consumo e dos imperativos da hiperperformance e excelência (Aubert, 2004a; Aubert 2004b). 
Se Castoriadis (2002) e Palmade (1990) defendem um processo de crise, é porque essas significações deixaram de ocupar uma posição central em nossa sociedade e nenhuma totalidade de significações imaginárias emergiu para assumir a função dessas escoras, o que nos conduz à constatação que vivemos um período de transição e transformação. No âmbito da escora familiar, cabe enfatizar que não se trata também de se remeter a uma família cristalizada, impressa nos moldes tradicionais da sociedade patriarcal do século $\mathrm{XX}$, nem tampouco de buscar, mediante uma óptica saudosista, um tipo de família idealizada. Para além desses postulados, a atenção deve se dar, doravante, ao fato de que algumas significações sociais fundantes de nossa cultura foram deslocadas e alteradas consideravelmente.

Não obstante, se foi enfatizado que o deslocamento dessas escoras não é suficiente para a instauração de uma crise, é porque a espinha dorsal desse processo remete à perda de um sentido apreendido como imperecível de nossa sociedade, que faz com que fiquemos sem bússola e alheios à dimensão coletiva do social. Por meio de uma breve incursão pela modernidade, é possível constatar que sua instituição se consolidou mediante a emergência de duas significações imaginárias centrais, opostas às escoras

${ }^{3}$ De acordo com Lyotard (1986), o saber não se reduz à ciência,que constitui um subconjunto do conhecimento. Este, por sua vez, compreende um conjunto de religiosas: a significação da expansão ilimitada do domínio da razão, que corresponde à dimensão capitalista das sociedades modernas, e a significação da autonomia individual e do social, que abarca o projeto libertário, democrático e revolucionário moderno (Castoriadis, 2002). Hoje, porém, inclusive essas significações sofreram mutações consideráveis. Mas qual seria, então, a tradução subjetiva contemporânea dessas significações?

A escora do domínio da razão e do progresso transladou-se na exacerbação do primado da racionalidade instrumental, que se intensifica em um mundo cada vez mais paradoxal. Se o projeto de progresso moderno dava suporte para a construção tanto de um sentido para a história quanto para o futuro, o discurso hegemônico tecnocientífico volta-se sobremaneira para o plano econômico e para a busca de sucesso individual, provocando contraditórios efeitos e prescindindo de uma lógica temporal e sequencial. A aquisição do saber, que outrora era indissociável da formação interior do sujeito e da convivialidade, se enfraquece e se desloca, pois o próprio saber, engendrado na lógica do consumo, passa a ser valorizado em razão de como pode ser vendido, consumido e renovado. Aqui, não se trata de negar os desenvolvimentos e agonísticas gerados pela produção de conhecimento, ${ }^{3}$ na disputa

enunciados que vislumbra compreender ou explicar certos objetos. 
econômica pelo poderio sociopolítico dos estados-nações, mas sim de reconhecer que ela deixa de ter um fim em si mesmo e se coloca a serviço do utilitarismo. Inclusive a noção de valor, nesse sentido, é enviesada à medida que respeita a ética do resultado. A perda de um sentido imperecível de nossa sociedade, comocoletividade, vincula-se também a tal premissa. Ou seja, hoje as identidades constituem-se e apoiam-se principalmente em identidades do domínio do ter e do poder. Logo, cabe o questionamento: uma coletividade, com uma rede precária de identificações, pode ainda ser considerada uma coletividade? Qual seu sentido e laço fundante?

A significação da autonomia, a seu turno, parece passar tanto por um processo de ocultação prolongada quanto é confundida comumente com um pseudoindividualismo. Ambos, no entanto, tendem a centrar-se, mormente, em conflitos corporativistas e a se assentar sobre as virtudes e potencialidades do mundo do trabalho. O dogma do crescimento, nesse contexto, ganha novas roupagens e parece tomar o lugar de Deus. A corrida pelo mérito torna-se uma finalidade indiscutível, que transcende a perseguição por gratificações narcísicas e pela inscrição da identidade, no campo social (Gaulejac, 2010). As relações sociais se assentam mais na comparação do que na identificação. É dizer, a singularização se dá em um reduto ambíguo: busca-se a autonomia, mas mediante modelos predefinidos, sob a égide de uma lógica de concorrência que se inscreve em diversos domínios da existência e faz com que o desenvolvimento pessoal se reduza a embates, jogos de aparência e comparações constantes com o outro. Por conseguinte, se o discurso empresarial na atualidade ganha destaque considerável, é porque se pauta em um modelo de conduta ideal de expansão e eficácia, assim como se sustenta na promessa da construção de singularidade, admiração e destaque. Correlativamente, a exigência de autonomia carrega consigo o ideal narcísico de autoengendramento como forma máxima de sucesso.

A exigência de "autonomia" é em si mesma paradoxal, pois para afirmar uma singularidade irredutível, devemos necessariamente nos entregar aos moldes de socialização que nos são impostos. Ora, é preciso buscar a coerência diante de tais contradições. Devemos nos mobilizar em direção à afirmação de uma especificidade e tentar provar (para nós mesmos e também para os outros) que somos "fora do comum", que nos destacamos no tecido social (Gaulejac, 2010). Com efeito, o imaginário social do ideal de exceção e autonomia carrega em seu núcleo uma clara contradição. Preconiza-se que é preciso sobressair-se, ser excepcional e manter essa excepcionalidade. Esquece-se, todavia, que a excelência não se partilha. Como bem sublinha Gaulejac (2007, 
p. 83), a etimologia do termo vem do latim excellentia, do verbo excellere, que significa "sair da porção, superar, ter a vitória sobre”. Desse modo, ao passo que é impossível todos serem "fora do comum" simultaneamente, o discurso da excelência endereça todos os "semelhantes" a um ideal mítico inacessível, por meio de um projeto de perpétua superação. Portanto, a excelência não mais se refere a um atributo durável, de qualidade superior, senão que adquire um caráter de mobilidade, que remete à necessidade de ascendência constante. Alcançar objetivos satisfatoriamente ou fazer o trabalho corretamente não é mais suficiente para ser reconhecido. É preciso ser brilhante, fora do comum, excelente. A significação social da autonomia, em síntese, em vez de ser concebida como uma chance, uma oportunidade, parece colocar-se como um imperativo, um pesado fardo que todos têm a obrigação de carregar. Outrossim, consolidase no plano social um movimento de "pejoração da média", associando-a com figuras como a mediocridade, a descrença e a fraqueza. No plano psíquico, por fim, ser mediano passa a implicar sentimentos de vergonha, inferioridade, pessimismo e incompetência.

Se prefiguramos, então, um processo de transformação das escoras centrais da modernidade e, ademais, admitimos a perda de um sentido de unicidade e de valor da coletividade, cabe a essa altura apresentar o surgimento de uma terceira escora de sentido, relacionada ao universo do trabalho, que apesar de tampouco carregar consigo um sentido imperecível, imprime marcas indeléveis em nossa cultura e nos ajuda a compreender como a crise de sentido se apresenta em uma sociedade cada vez mais demandante de sentido. Sublinha-se, portanto, um fenômeno, vinculado à lógica financeira e do consumo, que faz com que as identidades e culturas de classe se dissolvam, transferindo representações e problemáticas que antes remetiam ao coletivo, para o plano individual.

No âmbito do trabalho, a fragilidade dos empregos e a fluidez social, embora não atinjam igualmente as diversas categorias sociais, se revelam categóricas. $\mathrm{Na}$ sociedade industrial, a norma predominante condicionava o sujeito à adaptação de uma posição social estável e estanque, que por meio de um processo lento e incomum, possibilitava uma progressiva ascensão na escala social, sem, contudo desprender-se de seu meio de origem. Atualmente a estabilidade e a qualidade dão lugar à mobilidade e ao ideal, que se impõem como normas (Gaulejac, 2007). Todo ser humano responde, inicialmente, às suas condições concretas de existência, isto é, à sua herança familiar, assim como aos capitais sociais, econômicos, culturais, biológicos, afetivos e simbólicos dos quais dispõe. Cada indivíduo conta também com suportes distintos (e 
desiguais) para assegurar sua existência social. No entanto, embora as possibilidades de ascensão social tenham fortes raízes na dependência das heranças sociais e, portanto, o peso da origem social cumpra papel notável na reprodução das desigualdades, é fato também que a sociedade atual é marcada pela instabilidade das posições individuais. A "luta pelos lugares"4 e a corrida pelo mérito substituem a "luta de classes" (Gaulejac\&Taboada-Léonetti, 1994).

Os indivíduos são confrontados com uma luta cada vez mais solitária para existir socialmente. Uns em uma competição encarniçada para entrar na elite, outros para conservar posições adquiridas; outros, por fim, confrontados com uma desinserção social, andam desesperadamente errantes para encontrar ou reencontrar uma situação e um reconhecimento. (Gaulejac, 2007, p. 242)

No contexto laboral, essa escora de significação prediz que todos nós devemos nos libertar de nossas amarras sociais, bem como dos obstáculos que nos impedem de alcançar o sucesso. A aspiração de destaque social e da visibilidade torna-se um ditame das carreiras profissionais. $\mathrm{O}$ trabalhador flexível, polivalente, versátil, com grande capacidade de adaptação, substitui o homem de profissão, que se constituía por meio de uma

${ }^{4}$ Destaca-se que Gaulejac e Taboada-Léonetti (1994) se servem de um jogo de palavras, proveniente da proximidade da semântica das palavras francesas "luttedesplaces" e "luttedes classes", que se perdera na tradução do português. Mais ainda, no idioma francês, identificação profissional que ancorava sua posição social. Com efeito, a desagregação da pertença e consciência de classe, que se dava de forma intergeracional, dá lugar à emergência de um novo conjunto multipolar, estratificado e centrado em uma disputa para ocupar posições valorizadas e de prestígio (Gaulejac, 2011). O cenário hipermoderno, cibernético, informacional e marcado por um ecletismo de mercado anuente aos imperativos do laissez-faire, faz com que inclusive as identidades nacionais entrem em declínio, em face da homogeneização cultural. Quanto mais a globalização produz indiferenciação, mais os modelos culturais tendem a se interpenetrar. $O$ que antes ocupava o lugar de uma identidade permanente, hoje é substituído por múltiplas identidades e tribos, sucessivos e concomitantes pertencimentos. É isso, pois, que faz com que o indivíduo não possa se fixar duravelmente a algo (Gaulejac, 2010).

A pulverização das classes, no entanto, não significa o fim das classes, nem tampouco implica a amenização das desigualdades. No Brasil, embora as populações mais pobres tenham melhorado suas condições de vida economicamente, os ricos estão ainda mais ricos, de modo que o abismo da desigualdade se mantém e a concentração de renda entre os mais ricos

a palavra "place" remete a um lugar não somente concreto, mas também subjetivo, em que determinada posição é apreendida no plano imaginário em razão de determinados contextos. 
permanece estável desde 2006. Mais ainda, de 2006 a 2012, a população equivalente a 1\% mais rica do Brasil se apropriou de aproximadamente $25 \%$ da renda total nacional (Medeiros, Souza \& Castro, 2015). Cabe sublinhar ainda que de acordo com o "ranking da igualdade" feito pelo Banco Mundial, que estipula medidas de concentração de renda, o Brasil ocupa a $141^{\text {a }}$ colocação. Portanto, a mobilidade social, malgrado tenha se diversificado, ainda é exceção em nosso país. Logo, quanto mais se celebra o mérito pessoal, mais se legitima o mundo de competição permanente, elevando os "ganhadores" e rebaixando os "perdedores". É fundamental ressaltar, porém, o caráter volúvel e efêmero desse fenômeno. Qualquer um pode se tornar repentinamente um "perdedor", um problema social a ser excluído. Basta não responder satisfatoriamente aos critérios da excelência, performance e do espetáculo, que o indivíduo é descartado.

Embora a imersão social em mundos e experiências diversas tenha se tornado mais frequente, não houve aumento efetivo das possibilidades de ascensão social. Eis, aqui, um paradoxo. É constatada a presença de

\footnotetext{
${ }^{5} \mathrm{E}$ evidente que não acreditamos que os indivíduos devem ser iguais em tudo. Hierarquias e inclusive certo grau de diferença distributiva é inerente ao sistema capitalista no qual estamos inseridos. É possível, porém, ser igualitário sem ser igualitarista. Para tanto, é preciso apreender que desigualdades sociais pressupõem, em seu núcleo, relações assimétricas de natureza discriminatória e excludente. Mais ainda, segundo Srour (2005), “as diferenças sociais não são
}

uma significação, cuja doutrina carrega a prerrogativa de que cada indivíduo tem a oportunidade e escolha de cambiar seu destino, mas, por outro lado, estamos longe de um cenário de equiparação de condições e oportunidades reais de ascensão social. A mobilidade profissional, portanto, de acordo com essa escora de significação, se lograria conforme a criação de valor e desenvolvimento de talentos individuais. Contudo, para além de qualquer posicionamento de desrresponsabilização e evitando incorrer no equívoco de se utilizar de caricaturas ou exceções para elevá-las ao estatuto de regras gerais, é fundamental que nos questionemos sobre as condições concretas de igualdade de oportunidades - o que é muito diferente do igualitarismo $-{ }^{5}$ sobretudo no que diz respeito à formação permanente, bem como ao momento de inserção profissional e inserção pelo diploma. Ademais, há ainda que se considerar fatores outros, como a superação de preconceitos, da resignação coletiva, da criminalização da pobreza, o reconhecimento da diferença e a falta de eficiência na garantia dos direitos básicos do ser humano. Os governos,

desigualdades sociais. [...] Porque há desigualdade social quando o acesso real aos meios de produção for franqueado a uns e vedado a outros, quando alguns têm seus interesses defendidos pelo Estado em detrimento de outros. Isso produz a fratura em classes sociais e um desfrute amplamente diferencial dos meios de subsistência" (p. 250). 
outrossim, não demonstram interesse na mudança desse paradigma.

\begin{abstract}
Não é mais a luta de classes que marca o discurso do político, e sim a luta pelos lugares.

Dar a cada um a possibilidade de ter uma existência social em uma sociedade na qual os indivíduos têm medo de a perder [...]. A luta pelos lugares confronta cada um com sua contradição entre um projeto individual de sair-se bem e um projeto coletivo de melhorar a sorte daqueles que partilham de sua condição. (Gaulejac, 2007, pp. 258-259, grifo nosso)
\end{abstract}

Quando a economia ascende sobre a política, esta não mais se preocupa com a governabilidade dos homens (no sentido da busca de um equilíbrio entre a economia, o social e a política), senão que visa assegurar a manutenção das forças econômicas e a obter a confiança dos mercados (Gaulejac, 2007). $\mathrm{Na}$ esfera política, paradoxalmente a economia passa a se opor ao social. A política que vislumbra atingir a confiança do povo, mormente, perde a confiança dos mercados. Nossa sociedade reduz os cidadãos a consumidores, produtores e clientes, gerando cada vez mais desencantamento, fechamento em si mesmo e incoerência. $\mathrm{O}$ dinheiro e o trabalho, em vez de serem concebidos como meios de subsistência, tornam-se a finalidade de nossa existência (Gaulejac, 2011). Destarte, a existência de cada ser humano começa a passar pelo valor da materialidade de um status, que é avaliado segundo rendimentos financeiros, vividos muitas vezes como incoerentes. Ao passo que o trabalho torna-se tributário ao emprego, o desemprego, nesse reduto, amiúde é apreendido como o produto de um fracasso pessoal. Pulveriza-se o pensamento complexo e o indivíduo se vê como um pária, que necessita constantemente adaptar-se às novas demandas do mercado. A descrença no estado, nas coletividades, na política e em seus partidos, correlativamente serve como um mote central para adesão ao discurso empreendedor, que enaltece as individualidades e coloca tão somente $\mathrm{o}$ sujeito como figura responsável pela garantia de melhores condições para sua vida. Assim, o ganho pelo ganho distancia-se de qualquer função social. Ora, ganhamos porque temos valor ou temos valor porque ganhamos? Em outros termos, nossa sociedade não vê mais motivos e sentido para travar lutas coletivas, orientadas por um sentimento imperecível de pertença. Nossa autorrepresentação se inverteu: parece que não mais as individualidades compõem uma coletividade, senão que são sobrepostas, formando grupos intersectados e ligados estritamente por sistemas de interesses sem vinculação concreta, mas que ora se coadunam, ora se desarmonizam. 


\section{Representações, Finalidades e Modos de} Sofrimento no Trabalho

Ao resgatar que as significações sociais têm um tripé dimensional, é possível dizer que essa terceira escora de significação imaginária implica, em primeiro lugar, a estruturação de uma representação de um mundo estratificado, heteróclito, instável, cuja vida não é vivida como um destino coletivo, mas se reduz a uma rede de histórias pessoais, centradas no aqui, no agora e imersas em um contexto de pessimismo e descrença generalizados. A posição social ocupada por cada um de nós e, por conseguinte, a "luta pelos lugares", pulveriza quaisquer confrontos de classe e individualiza os problemas sociais. A coesão social tornase dependente tão somente de ações e discursos localizados. No trabalho, a diversificação das formas de emprego e as negociações coletivas prescindem do plano nacional ou interprofissional e se restringem aos planos e acordos com a empresa. Como sublinhou Castel (2003), passamos de um mundo de coletivos solidários para uma sociedade de indivíduos precários no trabalho. Entraves econômicos e políticos que alhures eram coloridos pela díade burguesia industrial e proletariado, ou entre direita e esquerda, tiveram suas significações deslocadas mediante o enfraquecimento de seus "sujeitos históricos". O problema da exploração, que remete ao coletivo, se reduziu à perspectiva da exclusão na mundialização financeira (Gaulejac, 2007). Assim, pragmaticamente subentende-se que favorecendo o crescimento e gerando novos empregos o problema se resolve. Os questionamentos sobre a natureza e condições desses empregos, contudo, permanecem em espaços periféricos.

Em segundo lugar, essa significação designa uma finalidade cardeal da existência, que se coloca como imperativo categórico: o indivíduo deve consumir o maior número de objetos possível, é condenado à ultrapassagem de si, deve acumular gratificações narcísicas incessantemente e qualquer obstáculo encontrado em seu percurso tende a ser traduzido como fracasso ou insuficiência pessoal. As finalidades, nessa escora de significação, prescindem da unicidade de um coletivo e valoram a potencialidade das individualidades. A ética do resultado, nesse sentido, faz com que inclusive a educação e os modelos familiares sejam tomados por essa lógica utilitária, passando a funcionar como propulsora desse paradigma.

À medida que nossa sociedade passa a ser vista como uma grande empresa, há um movimento emergente de "rentabilização do humano" (Gaulejac, 2007). Respaldado pelos ideários do individualismo, da excelência e da competição, essa escora de significação preconiza que cada indivíduo deve ser o empreendedor de sua própria vida, fixando para si objetivos claros e precisos, avaliando 
seus desempenhos no máximo de registros possíveis (devemos gerenciar nossos corpos, capacidades intelectuais, absorver o máximo de informações possíveis, etc.).

A família, nesse contexto, é concebida como uma pequena empresa que não deve falhar em seu principal objetivo: estruturar indivíduos excelentes em todos os domínios de suas vidas. O dinheiro, aqui, é apreendido como um aguilhão que favorece a mobilização psíquica ativa e incessante, fazendo com que os indivíduos busquem "sempre mais" e se comprometam desde suas infâncias com a corrida ao mérito. $\mathrm{O}$ discurso não se volta mais para o durável, o sólido e o contínuo, mas sobre a capacidade de adaptação e de mudanças. O foco se dá mais no fomento de formas de personalidades flexíveis, capazes de construir e reconstruir múltiplas personalidades (Aubert, 2004a), do que na formação plena, que coloca a cidadania e a convivialidade como valores centrais da vida em sociedade. Assim como a família, a escola segue modelos que valorizam a aplicação de programas, serializações, disciplinas, competição, classificação e seleção, preparando seus alunos mais para entrar no mundo da produção do que para viver plenamente em sociedade.

Por fim, em terceiro lugar, a referida escora de significação reflete modos específicos de afetos, investimentos subjetivos e sofrimento. É notável que o trabalho ocupa uma função central na vida de todos nós, mas qual a natureza hegemônica dos investimentos subjetivos direcionados ao universo laboral atualmente? Como se expressam as formas de sofrimento e malestar nesse reduto? Ao considerar a era do capitalismo industrial, é constatado que as horas de trabalho foram reduzidas, benefícios foram obtidos e a proteção dos trabalhadores, sobretudo física, progrediu em muitas áreas. No entanto, se as condições objetivas de trabalho são mais confortáveis atualmente, as condições subjetivas parecem se degradar (Gaulejac, 2011). Atualmente, os transtornos mentais representam a terceira maior causa de longos afastamentos do trabalho por doença, gerando um custo médio de 210 milhões de reais para novos benefícios previdenciários anualmente. Esses afastamentos estão atrás apenas dos traumas e doenças osteomusculares (Lesão por Esforço Repetitivo e Distúrbio Osteomuscular Relacionado ao Trabalho). Dos casos mais frequentes, destacam-se os transtornos de humor (sobretudo as depressões), em primeiro lugar, seguidos dos transtornos de ansiedade (síndromes do pânico, principalmente) e estresse (vinculados, por vezes, a casos de assédio moral $^{6}$ e sexual). Outro dado representativo, segundo pesquisa realizada pelo Instituto de

${ }^{6} \mathrm{~A}$ esse respeito, ver Marangoni, Viana Braz e Hashimoto (2016). 
Psiquiatria do Hospital das Clínicas da Faculdade de Medicina da Universidade de São Paulo, é o uso cada vez mais frequente de substâncias psicoativas por trabalhadores, a exemplo do álcool e outras drogas incluindo aqui medicações lícitas (Bernardes, 2013).

$\mathrm{Na}$ hipermodernidade, o excesso se desvela um elemento-chave, regulador das afetações e dos sentimentos. No tempo, nos espaços, na cultura e nas compulsões, o excesso parece sempre se presentificar. $\mathrm{O}$ tempo cronológico, sequencial e irreversível, dá lugar a um tempo "imaterial", "atemporal" (Aubert, 2004b), que é fundado sobre a tecnologia e que prescinde da durabilidade e de referências acategorias tradicionais do passado e do futuro. A brevidade estabelece os contornos de uma nova forma de relação com o tempo, que é marcada por dois domínios fundamentais que eternizam o presente: a urgência e a prevalência do instante (Aubert, 2003). É evidente, porém, que cada um de nós opera com esse corolário de modo singular e em consonância com nossa história de vida. No entanto, é também notável que em maior ou menor grau somos afetados e estamos assujeitados às imposições do imperativo dessa significação imaginária. Por mais que tentemos, acabamos nos deparando com a impotência diante de algo que nos ultrapassa.

A referida escora de significação, marcada pela frivolidade e incredulidade, pulveriza a possibilidade da construção de uma autorrepresentação sólida, apreendida como centro de sentido e de valor da coletividade. Com base em Augé (2007), é possível apreender que há atualmente uma espécie de crise de sentido, em uma sociedade cada vez mais demandante de sentido. Intensificada pela superabundância de acontecimentos, por múltiplas experiências de territorializações, bem como pela urgência do tempo, tal perda de sentido é a expressão de um mundo dominado por massivas prescrições, mediações técnicas e, portanto, vivido como incerto e dissonante. Se de um lado a pulverização das certezas e estabilidade dávazão a mudanças e transformações constantes, de outro lado traduz o aumento das incertezas e fragilidades (Castel, 2009). Transversalizando quaisquer crises políticas ou econômicas, nos remetemos a uma crise simbólica, caracterizada pela exacerbação da insegurança e pelo sentimento de perda de sentido.

Distanciando-se da sociedade moderna, marcada pela interioridade e reflexão sobre si mesmo, nossas escoras de significações imaginárias se assentam sobre o paradoxo subjetivo do autocentramento direcionado à exterioridade. A dimensão estética, o imperativo do espetáculo, a valorização do "olhar do outro", nesse contexto, emergem em primeiro plano (Freire-Costa, 2004). $\mathrm{Na}$ mesma perspectiva,Lipovetsky (2007) versa que ao 
mesmo tempo em que há o ditame de satisfação de todos nossos desejos, os adoecimentos ligados à frustração crescem de maneira exponencial. Quanto mais se torna dominante o discurso de que nenhuma vontade deve ser reprimida, mais aumenta a incapacidade de lidar com a insatisfação. O indivíduo se depara comumente com a vergonha, em detrimento da culpa, e sente a constante necessidade de destaque social. De modo algum é defendido aqui que o laço social é descartado, mas sim que, na hipermodernidade, ele se desgasta, se "afrouxa" substancialmente e é reduzido a um esforço global de agregação de ações em que cada indivíduo tende a buscar sua própria vantagem e lucro (material ou simbólico).

Tanto o "culto da urgência" (Aubert, 2003) quanto alógica da excelência (Aubert \&Gaulejac, 1991/2007) exigem um investimento ilimitado na busca pela rentabilização do tempo e sobreposição social. Com efeito, erigem-se novas formas de sofrimento, que se exprimem no universo laboral, na figura da angústia do fracasso, do receio de não estar à altura das atribuições recebidas, do medo excessivo do futuro, sentimento de impotência, cansaço de si, assim como outras manifestações como as depressões nervosas, o esgotamento profissional (burn out), a hiperatividade laboral e, inclusive, o suicídio ligado ao trabalho. Trata-se, em última instância, de manifestações psíquicas que refletem as novas estruturas e organização do trabalho em nossa sociedade. São reflexos, portanto, de uma escora de significação que faz com que a ética do desejo seja tamponada pela ética dos resultados e da produção. O crescimento e a luta pela ultrapassagem pessoal são considerados o motor do progresso social. A moral voltada ao bem comum e a convivialidade, em consonância, é solapada pela moral do risco, da inovação e do progresso. Sobrepõem-se, sobretudo, nas empresas, os managers que valorizam condutas dinâmicas, corajosas, indivíduos que enfrentam os riscos da incerteza do mercado.

As formas predominantes de malestar e sofrimento no trabalho constituem algumas imagens dos modos de investimentos feitos pelos indivíduos hipermodernos, que são impelidos a introjetar as leis do mercado, a seguir a lógica do imediatismo e a produzir cada vez mais, com cada vez menos pessoas e sempre com menos tempo. Desse modo, a intensa mobilização psíquica e flexibilidade constante, cedo ou tarde, produzem o esgotamento. Esse sentimento produz, então, modos de sofrimento específicos, produtos do individualismo e da corrida ao mérito, que podem se exprimir de diferentes formas. Por vezes, há a emergência de sentimentos constantes de não poder satisfazer as exigências de excelência solicitadas pela empresa, assim como há o receio de não estar à altura das atribuições recebidas, o medo do 
futuro, o pessimismo, a incredulidade e o sentimento incessante de impotência, nervosismo ou irritação. Aubert (2004b) discorre, ainda, sobre fenômenos de alterações patológicas de comportamento -O trabalhador ora se mostra completamente simpático, ora reage com um ódio incontrolável. Pode haver, nesses casos, em face de exigências cada vez mais inflexíveis, a fragmentação e o rompimento do equilíbrio psíquico do trabalhador.

Em consonância, o esgotamento profissional (burn out), assim como as depressões ligadas ao trabalho, é considerado produto do superinvestimento profissional. O burn out emerge, geralmente, quando há um grande dispêndio de energia para lograr um objetivo irrealizável. Manifesta-se sob a forma de exaustão física e emocional, despersonalização, quadros agudos de estresse e sensações de estar sendo consumido por dentro. "O aparelho psíquico fica como um elástico demasiadamente esticado, como se não pudesse relaxar" (Gaulejac, 2007, p. 218). A depressão, por sua vez, faz com que o trabalhador sinta lentidão psicomotora, incapacidade de concentração, desgaste físico e emocional, insegurança, inibição e tristeza generalizada. Aubert e Gaulejac (1991/2007) postulam que essa

${ }^{7} \mathrm{O}$ Eu é uma instância da personalidade responsável pela mediação dos interesses da totalidade da pessoa (ele é dependente tanto das reivindicações do Isso quanto das exigências e imperativos do Supereu). Do ponto de vista da economia pulsional, o Eu surge como um fator de ligação dos processos psíquicos. Do forma de depressão, nesse contexto, é antagônica à paixão. Quando a paixão se esvai, quando há a quebra dos laços amorosos do indivíduo com seu trabalho (a perda do ideal), emerge a depressão, desvestindo as contradições inerentes à relação estabelecida outrora com a empresa. Segundo Aubert (2008), essas respostas psicopatológicas representam tentativas de desconexão em relação a ambientes tomados pela aceleração e que não mais podem ser suportados.

O trabalho, nesse contexto, amiúde se revela o operador causal e principal denominador das experiências limites subjetivas descritas. No registro das intensidades, é comum observar modalidades de mal-estar que passam pela suspensão do $E u^{7}$ anunciando o fantasma da perda de si, que se coloca como signo insofismável. Tal como nas depressões nervosas relacionadas ao trabalho, há a emergência de um corolário de apatia e exaltação, inscrito na irritabilidade e explosões repentinas de raiva, que comumente são acompanhadas de tentativas do sujeito em racionalizar suas reações com algum elemento contextual. Contudo, a desproporção reativa ultrapassa de modo patente o motivo aludido, desvestindo o indivíduo em uma espécie de despossessão de si (Birman, 2014).

ponto de vista dinâmico ele representa o polo defensivo da personalidade; “[...] põe em jogo uma série de mecanismos de defesa, estes motivados pela percepção de um afeto desagradável (sinal de angústia)" (Laplanche \&Pontalis, 2001, p. 124). 
Esse corolário de investimento está, ainda, intimamente ligado às diversas formas de adicção no contemporâneo. Interessa-nos, particularmente, as designadas de hiperatividade laboral. Mobilizados pelos ditames da urgência, os work-a-bolics veem a organização como uma droga, da qual não conseguem se desvincular. Do mesmo modo que o toxicômano concebe o gozo sem limites, os também denominados workaddictstêm a ilusão de que a empresa lhes proporcionará o gozo e ideal que tanto buscam (inexistentes na realidade). Da Silva e Hashimoto (2012), a esse respeito, sublinham que essa relação com a organização, além de funcionar como uma bengala de sustentabilidade da cultura do espetáculo por proporcionar ao trabalhador uma ilusão de identidade -, faz com que o indivíduo sinta que está próximo do ideal almejado. Trata-se, portanto, de um percurso insidioso, pois o trabalhador, alimentado pelos imperativos da excelência e da performance, vê sua conduta como uma forma de proteger sua profissão ameaçada pela competitividade. Ele encontra, pois, uma justificativa para sua existência.

Essa relação de dependência com o trabalho, segundo Gaulejac (2007), apresenta os mesmos sintomas que algumas drogadições. Em um primeiro momento, o

${ }^{8}$ De acordo com Laplanche e Pontalis (2001), o Ideal do Eu é " [...] uma instância da personalidade resultante da convergência do narcisismo (idealização do eu) e das identificações com os pais, com os seus substitutos e com os ideais coletivos. Enquanto instância diferenciada, o Ideal do Eu constitui um modelo a que o sujeito procura conformar-se" (p. 222). Diz respeito, hiperativismo

$\operatorname{traz}$

sensações

psicoestimulantes, como gratificações narcísicas, hiperestimulação sensorial, intenso reforço grupal sobre a empresa e ilusão de fusão entre Eu e Ideal do $E u{ }^{8} \mathrm{Em}$ um segundo instante, contudo, outros efeitos se fazem sentir, como a necessidade incoercível de trabalho, angústia das férias, enfraquecimento das capacidades criativas e doresdecabeça constante. Não obstante, particularmente nesses casos a sobrecarga de trabalho é apreendida na mesma dimensão do estresse, ou seja, ela é considerada normal, uma competência e, portanto, é aceita voluntariamente. Embora seja produto de escolhas pessoais, ela é vivida comumente como resposta às exigências da organização, como se o indivíduo nunca fizesse o bastante e como se o trabalho realizado jamais fosse satisfatório. A hiperatividade laboral, longe de ser concebida como uma condição psicopatológica, é compreendida como

\footnotetext{
[...] fonte de orgulho, acompanhado de uma queixa pouco convincente de "vitimização": “não aguento mais”, “estou esgotado”, “não tenho mais tempo para mim". Ela traduz um superinvestimento no trabalho que vem a preencher um sentimento de falta. [...] A combinação de uma expectativa de reconhecimento insatisfeito, de critérios
}

pois, a uma projeção no futuro e no social, da imagem de si, sustentada pelo Supereu. Trata-se, em resumo, de uma instância da mobilização, da superação, da incitação, que empurra o Eu em direção aos ideais, a reconquista de uma perfeição perdida. 
flutuantes que definam concretamente $O$ trabalho a ser feito e a incerteza diante da lógica de obsolescência, produz um sentimento de ameaça. (Gaulejac, 2007, p. 219)

Com efeito, entendemos que no horizonte desse mecanismo, há uma tentativa ilusória de responder à incompletude narcísica, às exigências de desempenho e às ameaças implícitas de demissão, que se traduz em um forte investimento subjetivo no trabalho (Rhéaume, 2004). Em um contexto em que a desigualdade se multiplica, a exclusão e injustiça banalizam-se e a competitividade e o individualismo proliferam-se, o superinvestimento no trabalho se revela uma forma de defender a profissão ameaçada. Trata-se também de uma tentativa de evitar ou reduzir o sofrimento desencadeado pelas incoerências vividas no cotidiano ocupacional. Todavia, embora seja um mecanismo naturalizado, Rhéaume (2004) alerta que a hiperatividade não repousa sobre uma edificação identitária estruturante, mas sobre um desvio narcísico patológico socialmente construído.

O trabalho (Reschke, 2013) desenvolvido pelaInternational Stress Management Association(ISMA - BR), nesse sentido, atesta as referidas constatações. Ana Maria Rossi, coordenadora da pesquisa, que contou com a participação de 745 trabalhadores de São Paulo e Porto Alegre, notou que $53 \%$ de sua amostra evitavam folgas e $41 \%$ tinham medo de tirar férias. Os motivos alegados pelos profissionais para explicar tais atitudes foram, além do medo de perder espaço e prestígio em decorrência da alta competitividade, o aumento dos conflitos familiares, a "falta do que fazer", a dificuldade de se desligar mentalmente do trabalho, assim como outras queixas relacionadas a despesas adicionais de férias e visitas ou hóspedes que “causam excesso de tarefas domésticas e atividades sociais". A coordenadora relatou, ainda, casos em que funcionários faziam ligações para colegas, durante suas pausas, em busca de notícias sobre o trabalho. A pesquisa revelou, em suma, parte significativa das questões apontadas por nós. Deparamo-nos, amiúde, com indivíduos que não toleram o enfrentamento com sua interioridade, tampouco com as problemáticas da alteridade e do reconhecimento de si comosujeitos psíquicos, vinculados às historicidades genealógicas que lhes são próprias.

$$
\text { Relacionado também }
$$
superinvestimento no trabalho, e sob a égide da luta pelos lugares, o trabalhador comumente tem medo de perder não somente seu trabalho, mas também sua posição social e, principalmente, os ganhos materiais e simbólicos provenientes de seu labor. O medo impõe uma dura condição para que o trabalhador desenvolva suas atividades. Além de conduzir um quadro de submissão, ele engessa o debate coletivo e de deliberação. Há, nesse cenário, o medo em 
diversas facetas: medo de revelar suas próprias angústias, de ser interpretado como "incompetente", medo de que ao expor suas dificuldades tais informações possam ser usadas contra si na "próxima lista de demissões" etc. Por meio dessa fenomênica, é possível perceber como “[...] os sinais exteriores de competência e eficácia repousam sobre a preocupação de ocultar metodologicamente todas as falhas que se não consegue corrigir" (Dejours, 2001, p. 55). Embora deletéria, a utilização do medo como motor de mobilização da inteligência no trabalho ainda é frequente. Sob a influência do medo, por exemplo, e com a ameaça de demissão pairando sobre todos trabalhadores, a maior parte dos indivíduos se mostra efetivamente capaz de se mobilizar em direção a um arsenal de inventividade para melhorar sua produção e se sobrepor em relação a seus colegas de trabalho, de modo a ficar em uma posição que não ofereça perigo, quando da elaboração de processos de dispensas (Dejours, 2001).

No contexto da corrida ao mérito e do fomento do individualismo, o que outrora era considerado um conflito de ordem moral ou um problema social atualmente é considerado natural, inevitável e, logo, cabe a cada indivíduo lidar com isso no plano pessoal. A representação social que há em torno do estresse parece figurar claramente esse fenômeno. Se em outro contexto era considerado um fator ansiogênico, que produzia psicopatologias (e que, portanto, podia-se combater e evitar, por meio de uma planificação dos sistemas organizativos gerenciais), na contemporaneidade o estresse é considerado natural e imanente à conjuntura organizacional das grandes empresas. Cabe, inclusive, a cada trabalhador, “empreender" seu estresse e traçar estratégias de gestão do tempo, buscando ser cada vez mais eficiente.

Por fim, o último ponto a ser abordado remete ao suicídio ligado ao trabalho. Dejours e Bègue (2010) observam, nesse sentido, que a partir dos anos 2000 ampliou-se a ocorrência de suicídios no trabalho, sobretudo na Europa. No Brasil, cumpre destacar a pesquisa realizada por Finazzi-Santos (2009), na qual demonstrou que entre 1993 e 2005, 253 bancários brasileiros cometeram suicídio (o que representa uma média de um a cada 20 dias), com a ressalva ainda de elevado índice de subnotificação. No agronegócio, em consonância estudos têm demonstrado correlações significativas entre o uso e/ou exposição a agrotóxicos, distúrbios psiquiátricos e o suicídio (Pires, Caldas \& Recena, 2005; Meyer, Resende \& Abreu, 2007; Bombardi, 2011). Segundo Venco e Barreto (2010), há nesses fenômenos a expressão de um quadro crescente de degradação das condições de trabalho, oriundos também do agravamento da pressão, urgência e dos ditames da excelência. 
Embora essa problemática seja pouco divulgada no espaço público, o fato de que o suicídio é por vezes visto como uma saída radical para problemas advindos do trabalho constitui um dado alarmante.

De acordo com Dejours (2005), essa forma de suicídio traduz a emergência de um tipo de sofrimento ocupacional inteiramente novo, que reflete um aviltamento profundo do viver. Indica, ainda, uma degradação dos laços sociais no trabalho. Ressalta-se, porém, que embora tenhamos edificado uma caracterização geral desse fenômeno, ele é potencialmente complexo e se apresenta em diversas facetas distintas. Os suicídios de fato não provêm de processos iguais em diferentes empresas.

A multiplicação da incidência de suicídios no trabalho não é apenas decorrente de injustiças, quedas em desgraça ou assédios morais. Resulta, principalmente, da terrível experiência do silêncio dos outros, do abandono pelos outros, da recusa de testemunho pelos outros, da covardia dos outros. A injustiça e o assédio que outrora teriam sido considerados experiências árduas ou dolorosas, podem, no atual contexto, degenerar brutalmente em crise de identidade. (Dejours\&Bègue, 2010, p. 47)

Todavia, comumente ele é fruto do modelo gestionário utilizado e da organização

${ }^{9}$ Evidentemente, devemos evitar generalizações. Em razão de sua complexidade, para apreendermos no plano concreto a questão do suicídio, é necessário traçar uma rigorosa análise etiológica de cada caso, do trabalho, que em última instância são agenciados pelas escoras de significação hegemônicas de nossa sociedade. Seus fatores podem ser múltiplos e variados: mudanças significativas nos processos de trabalho, sentidas como despersonalizantes; ausência de reconhecimento, estima e solidariedade; avaliações individualizadas de desempenho, com critérios nebulosos e desiguais; desorganização da produção; aumento excessivo da carga de trabalho; grandes conflitos entre equipes; substancial dificuldade de integração; competitividade exacerbada; pressão permanente; ambientes de rivalidades entre diferentes serviços e instâncias hierárquicas; desrespeito entre os trabalhadores; entre outros fatores.

Parece que a radicalização de algumas estratégias de gestão, portanto, por exigirem do indivíduo um hiperfuncionamento psíquico e corporal, abre espaço para a emergência dessas novas formas de suicídio.? A última mensagem, deixada no ano de 2007 por uma trabalhadora da empresa Sodexo, antes de se suicidar, coloca em evidência nossos postulados: "Eu não sou mais forte o bastante. Excesso de pressão, trabalho"(Aubert, 2008, p. 36, tradução livre). A referida funcionária, de acordo com seu marido, cerca de seis meses antes do ocorrido, vinha se queixando do excesso de

considerando a história do trabalhador e suas singularidades. 
pressão no trabalho. Nesse período, o esposo observou que ela chegava do trabalho demasiadamente cansada e passou a sofrer de crises depressivas. Logo, começou a fazer uso de antidepressivos. Seu companheiro destacou, ainda, que as pressões se intensificaram após algumas mudanças realizadas pela gestão. Dentre elas, se antes havia no grupo de restaurantes três gerentes, dois foram demitidos e sua esposa passou a fazer todo o trabalho sozinha, tornando-se responsável por administrar e organizar mais de 1.700 refeições que eram servidas por dia. "Ela passou a não suportar as exigências suplementares, de rentabilidade e a pressão do trabalho, por parte de seus superiores. [...] Ainda assim, ela amava seu trabalho e a empresa, na qual trabalhava há muitos anos" (Aubert, 2008, p. 37, tradução livre). Após deixar seu filho de dez anos, na parte da manhã, na escola, em vez de iniciar sua jornada, sua esposa se atirou de uma ponte, perto de seu trabalho. Em contraposição, de acordo com a autópsia, a trabalhadora se suicidou devido ao uso excessivo de antidepressivos.

Caso correlato é o de Dominique Peutevynck, que há 27 anos trabalhava na Usina Nuclear de Chinon, na França e em outubro de 2004 atirou-se nos trilhos de um trem, próximo a seu local de trabalho. Meses antes, Dominique havia recebido uma promoção e acumulou mais de 150 horas em seu banco de horas. No mês de junho, o engenheiro havia inclusive passado por um médico, que destacou o "risco psicossocial" do retorno ao trabalho. Todavia, nem o trabalhador nem a direção da empresa ouviram o médico, em razão da alta demanda de trabalho. Ressalta-se que o funcionário foi o sexto trabalhador a se suicidar, nos anos de 2003 e 2004, nas unidades da empresa. Igualmente, em fevereiro de 2006, um técnico de desenvolvimento da Technocentre de Guyancourt, centro de pesquisa e desenvolvimento da Renault, foi encontrado em sua casa enforcado. Junto a ele, havia um bilhete: "Eu não posso assumir mais nada, esse trabalho é demais para mim. Eles vão me demitir e eu estou acabado. É impossível fazer essa sua ‘top série’ de merda Gosn[sic]. E Hamel, desculpe-me, boa sorte". Entre 2006 e 2007, três suicídios ocorreram no referido centro de pesquisas (Gerschenfeld, 2010).

\section{Considerações Finais}

Com base em uma incursão nas transformações da organização do social na modernidade e na hipermodernidade, sobretudo em relação às escoras de significações imaginárias hegemônicas, prefiguramos a emergência de uma crise simbólica, que atinge as relações entre o econômico, o político e o social. Trata-se de um fenômeno de perda progressiva do sentido, proveniente de contradições, paradoxos e incertezas, vinculados ao 
conjunto de referências, códigos e linguagens que proporcionam sentido à ação coletiva e pulverizam qualquer sentido imperecível de unidade social (Gaulejac, 2007). Ao passo que se exacerba o individualismo, exalta-se o narcisismo, minimiza-se o que é da ordem do social, do coletivo e a produção de sentido torna-se um trabalho restritamente individual. Mais ainda, se perdemos importantes alicerces provenientes de instituições e escoras de significação outrora hegemônicas, preocupações, valores e ideais orientados ao bem comum assumem funções cada vez mais laterais (Viana Braz, 2014).

Não buscamos, contudo, direcionar nenhum tipo de olhar saudosista à modernidade, tampouco advogamos pelo "resgate dos valores modernos". Sabemos que toda sociedade é fruto de uma miríade complexa e multideterminada de fatores econômicos, técnicos, jurídicos, psicológicos e ideológicos. Portanto, historicamente buscamos localizar um conjunto de mudanças que consideramos basais, no seio das significações imaginárias sociais e, por conseguinte, nos modos de investimento subjetivos dos indivíduos com o trabalho. Decerto que o cenário laboral brasileiro é composto por um quadrante híbrido e multifacetado, oriundo de variáveis como o setor de mercado, estruturas organizacionais, natureza da atividade, modos de governança e arranjos políticos. Todavia, ao questionar as modalidades de investimento subjetivo e fontes de sofrimento, naturalmente nos interrogamos sobre o papel e evolução do trabalho na atualidade.

As novas formas de subjetivação do indivíduo contemporâneo, vinculadas às exigências cada vez mais intensas e paradoxais do mundo do trabalho, sobredeterminam a reação em detrimento da reflexão. Se o sujeito vê indeterminadamente no trabalho a finalidade de sua existência, o dispêndio de energia psíquica do hiperfuncionamento de si pode produzir uma sobrecarga patogênica. A particularidade dessas conformações, entretanto, reside no fato de que as fontes de sofrimento não são exclusivamente internas ou externas. Alimentados pelas âncoras discursivas das significações imaginárias apresentadas, os indivíduos cobram-se em excesso, sentem-se estimulados, reconhecidos e recebem significativas gratificações, simbólicas e materiais. A atividade, fruto do trabalho real, só passa a ser vivida como penosa e patogênica quando há a iminência do adoecimento.

Acreditamos, por fim, que o olhar sensível da Sociologia Clínica permite um tensionamento à lógica hegemônica e nos oferece uma terceira via de compreensão e intervenção, cuja pedra angular reside na negação da premissa que considera que os trabalhadores devem se adaptar inquestionavelmente às novas demandas do mercado de trabalho (para não serem 
excluídos), bem como se distancia de explicações que direcionam as problemáticas ao sujeito, individualizando toda sorte de sofrimento. Atualmente, destarte, para que possamos compreender o sofrimento e adoecimento vinculados ao trabalho, devemos nos orientar à análise da intersecção de problemáticas de ordens existenciais, organizacionais, sociais e econômicas. Não se trata, contudo, de analisá-las separadamente, mas de compreender como se entrecruzam e, mormente, como incidem nas formas de investimento subjetivo no trabalho e nas expressões de sofrimento, concernentes ao registro do trabalho vivido.

\section{Referências}

Aubert, N. (2003). Le culte de l'urgence. Lasociété malade du temps. Champs Essais. Paris: Flamarion.

Aubert, N. (2004a). Qui est l'individu hypermoderne? In N. Aubert (Org.). L'individu bypermoderne (pp. 11-24). Sociologie Clinique. Toulouse: Érès.

Aubert, N. (2004b). L'intensité de soi. In N. Aubert (Org.). L’individu bypermoderne (pp. 73-88). Sociologie Clinique. Toulouse: Érès.

Aubert, N. (2006). Hyperformance et combustion de soi. Études,10(405), 339-351.

Aubert, N. (2008). Violence du temps et pathologies hypermodernes. Cliniques Méditerranéennes,1(78), 23-38.
Aubert, N. (2010). La societé hypermoderne: une societé "par excès". In N. Aubert (Org.).La societé hypermoderne: ruptures et contradictions (pp. 23-34). Collection Changement Social. Paris: L'Harmanttan.

Aubert, N., \& Gaulejac, V. (2007). Le coût de l'excelence. Nouvelle Édition. Paris: Éditions du Seuil.(Trabalho original publicado em 1991).

Augé, M. (2007). Não-Lugares:introdução a uma antropologia da supermodernidade (6a ed., M.L. Pereira, trad.). Campinas: Papirus.

Bernardes, J. (2013). Transtorno mental resulta em longos afastamentos do trabalho. Agência USP de Notícias. abril de 2013. Recuperadoem 2 abril, 2017, de

http://www.usp.br/agen/?p=13653 8

Birman, J. (2014). O sujeito contemporâneo. Rio de Janeiro: Civilização Brasileira.

Bombardi, L. M. (2011). Intoxicação e morte por agrotóxicos no Brasil: a nova versão do capitalismo oligopolizado. Boletim DATALUTA, Presidente Prudente,10(1), 1-21.

Castel, R. (2003).La insécurité sociale. Paris: Seuil.

Castel, R. (2009).La montée des incertitudes:Travail, protections, statut de l'individu.Paris: Seuil. 
Castoriadis, C. (1982).A instituição imaginária da sociedade (G. Reynaud, trad., L.R.S. Fortes, rev. técnica). Rio de Janeiro: Paz e Terra.

Castoriadis, C. (2002).As encruzilhadas do labirinto. $A$ ascensão da insignificância $(\mathrm{R}$. Vasconcellos, Trad., v. 4.). São Paulo, Paz e Terra, 2002.

Da Silva, G. E., \& Hashimoto, F. (2012). Gestão estratégica: a toxicomania organizacional e a naturalização do sofrimento no trabalho. Enfoques,(11):1, 29-48.

Dejours, C. (2001).A banalização da injustiça social (4a ed., L.A, Monjardim, Trad.).Rio de Janeiro: Editora FGV.

Dejours, C. (2005). Nouvelles formes de servitude et suicide. Travailler, (1): 13, 53-73.

Dejours, C., \& Bègue, F. (2010). Suicídio e trabalho:o que fazer?(F. Soudant, Trad.). Brasília: Paralelo 15.

Dujarier, M. (2015). Le management désincarné: Enquête sur les nouveaux cadres de travail. Paris: Éditions La Découverte.

Ehrenberg, A. (1991).Le culte de la performance.Calmann-Lévy.

Finazzi-Santos, M. A. (2009). Patologia da solidão: o suicídio de bancários no contexto da nova organização do trabalho. Dissertação de Mestrado em Administração, 239f. Estudos Organizacionais e Gestão de Pessoas, Universidade de Brasília.
Freire-Costa, J. (2004).O vestígio e a aura:corpo e consumismo na moral do espetáculo. Rio de Janeiro: Garamond.

Gaulejac, V., \& Taboada-Leonetti, I. (1994).La lutte des places. Paris: Hommes et Perspectives.

Gaulejac, V., Hanique, F., \& Roche, P. (2012). La sociologie clinique: enjeux théoriques et méthodologiques. Toulouse: Éditions Érès.

Gaulejac, V. (2007). Gestão como doença social: ideologia, poder gerencialista e fragmentação social (I. Storniolo, Trad.). Aparecida: Ideias \& Letras.

Gaulejac, V. (2010). Le sujet face aux contradictions de la societé hypermoderne. In N. Aubert (Org.). La societé bypermoderne: ruptures et contradiction. (pp. 35-44). Collection Changement Social. Paris: L'Harmattan.

Gaulejac, V. (2011). Travail, les raisons de la colère. Paris: Éditions du Seuil.

Gerschenfeld, A. (2010). "Um suicídio no trabalho é uma mensagem brutal". Público. Portugal.Recuperado em 24 julho, 2016, de https://www.publico.pt/sociedade/ noticia/um-suicidio-no-trabalho-euma-mensagem-brutal-1420732

Hall, S. (2006) A identidade cultural na pósmodernidade (11a ed., T. T. da Silva e G. L. Louro, Trad.). Rio de Janeiro, DP\&A Editora. 
Laplanche, J., \&Pontalis, J.B. (2001). Vocabulário da Psicanálise (4a ed., P. Tamen, Trad.). São Paulo: Martins Fontes.

Lipovetsky, G. (2007). A felicidade paradoxal:ensaio sobre a sociedade do biperconsumo (M. L. Machado, Trad.).São Paulo: Companhia das Letras.

Lyotard, J. (1986). O Pós-Moderno (R. C. Barbosa, Trad.). Rio de Janeiro: José Olympio.

Marangoni, V. X. C., Viana Braz, M., \& Hashimoto, F. (2016). Bullying e assédio moral no trabalho: expressões do narcisismo contemporâneo. Cadernos de Psicologia Social do Trabalho,19(2),109-122.

Meyer, T. F.,Resende, I. L. C., \&Abreu, J. C. (2007). Incidência de suicídios e uso de agrotóxicos por trabalhadores rurais em Luz (MG), Brasil. Revista Brasileira de Saúde Ocupacional. São Paulo,32(116), 24-30.

Palmade, J. (1990). Posmodernité et fragilité identitaire.Malaise dans l'identification. Connexions, 1(55), 7-28. Pires, D. X.,Caldas, E. D., \&Recena, M. C. (2005). Uso de agrotóxicos e suicídios no Mato Grosso do Sul, Brasil. Caderno de Saúde Pública,Rio de Janeiro,21(2),598-605.

Reschke, C. (2013). Sem medo de se desligar. Você S/A,1(187), 84-86.
Rhèaume, J. (2004). L'hyperactivité au travail: entre narcisisme et identité. In N. Aubert (Org.). L’individu bypermoderne (pp. 89-102). Sociologie Clinique. Toulouse: Érès.

Srour, R. H. (2005). Poder, cultura e ética nas organizacõoes:o desafio das formas de gestão(2a ed.). Rio de Janeiro: Elsevier. Venco, S., \&Barreto, M. (2010). O sentido social do suicídio no trabalho. Revista Espaço Acadêmico,1(108),1-08.

Viana Braz, M. (2014). Sentido no trabalho e crise no tecido simbólico social: da Psicodinâmica do Trabalho à Psicossociologia. Laborativa, 3(2), 7385. 